\title{
Evaluating Methods of FAA Regulatory Compliance for Educational Use of Unmanned Aircraft Systems (UAS)
}

\author{
Ryan J. Wallace \\ Polk State College \\ Jon M. Loffi \\ Oklahoma State University \\ Anthony G. Ison \\ The Ison Law Firm \\ R. Michael Courtney \\ Polk State College
}

\begin{abstract}
Educational institutions on all levels of the educational spectra are interested in integrating unmanned aircraft systems into their curricula; however, complex Federal Aviation Administration (FAA) regulations and potential liability issues may deter some institutions from proceeding. Using document analysis of FAA regulations, legal interpretations, and precedent, the researchers codify and compare the methods by which educational entities can legally comply with the FAA's UAS regulations. This research overviews key issues with each method of compliance, including UAS flown as: a Public Aircraft Operation, under a Public Law 112-95 Section 333 Exemption, for hobby and recreational purposes under Public Law 112-95 Section 336 Model Aircraft Rules, and in compliance with the newly released 14 CFR Part 107 Regulations. The researchers present a recommended decision matrix for educational entities to evaluate their individual operational needs and select the most appropriate method of regulatory compliance for UAS integration. Additionally, the researchers present a proposed framework for an institutional review committee to evaluate and safely implement UAS operations at educational campuses.
\end{abstract}

As high schools, vocational schools, colleges, universities, and other institutions of higher learning move to integrate unmanned aerial systems into their curriculum, many are quickly discovering that the Federal Aviation Administration (FAA) compliance requirements are quite complex.

\section{Problem}

The FAA anticipates that the UAS market will balloon to more than 4.3 million hobbyist platforms and 2.7 million commercial systems by 2020 (Masunaga, 2016). The growth of the UAS industry has not been lost on educational institutions: many are eager to use UAS platforms both for research and in the classroom. 
With the FAA's recent release of 14 CFR Part 107 rules, many educational institutions are trying to determine how best to proceed. Attorney Debbie Esterak from Roger Moris \& Grover highlights some of the potential pitfalls for educational institutions integrating unmanned aircraft (Marchman, 2016):

The overarching issue is how school districts can use drones without running afoul of FAA regulations and also without putting themselves at risk for liability concerns... Luckily, the FAA's enforcement strategy is not to fine people right away for infractions, unless the operation is something really egregious. Right now, the FAA is taking an educational role and position. They want to get the word out about safety and security. It is important to be aware; however, that drone use is a federally regulated area and the laws are changing rapidly. Schools and school employees need to be aware that if they venture down the drone path, they do so with their eyes open and knowing the rules of the road. (p. 30, 32)

\section{Purpose}

This study sought to examine existing U.S. UAS regulations, case law, precedent, and legal interpretations to codify UAS restrictions as they apply to educational use. The overarching goals of this project are to:

- Consolidate relevant UAS regulatory information from multiple Federal Aviation Administration sources into a singular reference document

- Document available regulatory methods of compliance for educational institutions to conduct UAS operations

- Establish a comparative tool and decision-matrix for educational institutions to select the regulatory method of compliance that best meets their objectives for planned UAS operations

\section{Method}

This study utilized a qualitative design, using both document analysis and case study modes of inquiry. The study sought to answer the following research questions:

1. How can educational institutions legally incorporate use of Unmanned Aircraft Systems?

2. What legal or operational conditions or limitations are associated with educational use of Unmanned Aircraft Systems?

3. What legal issues are left unanswered by the FAA's guidance on educational use of UAS?

The study evaluated 50 regulatory references and legal interpretations from the FAA to triangulate relevant information to answer the posed research questions.

\section{Literature Review}

Legal use of unmanned aircraft is codified in Sections 331-336 of the FAA Modernization and Reform Act (FMRA) of 2012 (Public Law PL 112-95). These sections outline the establishment of research and development infrastructure, designation of UAS test ranges, execution of UAS integration safety studies, implementation of Arctic UAS operations, and adoption of a planned national UAS integration plan. The six page excerpt further charges the Secretary of Transportation and the Administrator of the Federal Aviation Administration with implementing interim authorization procedures for UAS operations as they apply to public governmental UAS platforms and UAS platforms and operations deemed safe for immediate integration (via Section 333 exemptions). The act also differentiates model aircraft usage from other types of UAS operations and restricts the Federal Aviation Administration from engaging in further regulation of hobby and recreational model aircraft activities.

On June 21, 2016, the FAA released the 14 CFR Part 107, Small UAS Rule. This regulatory addition codifies guidance on the airmen certification, operation, and maintenance of small, low-risk UAS platforms and goes into effect on August 29, 2016. 


\section{Methods of Compliance}

Currently, there are five methods of compliance by which an individual can legally operate UAS platforms in the United States (FAA, 2015b; FAA, 2016m):

- FMRA Section 334 Public Operation with a Public Aircraft and Certificate of Waiver or Authorization (COA)

- FMRA Section 333 Airworthiness Certification with Certificate of Authorization

- FMRA Section 333 Exemption with Certificate of Authorization

- FMRA Section 336 Model Aircraft Operations (FAA, 2014a)

- 14 CFR Part 107

\section{Public Operations}

FMRA Section 334 Public Operation with a Public Aircraft and Certificate of Authorization. Public Aircraft. According to the Federal Aviation Administration (2014b):

Although these [public aircraft] operations must continue to comply with certain general operating rules, including those applicable to all aircraft in the National Airspace System (NAS), other civil certification and safety oversight regulations do not apply to these operations. Accordingly, most aspects of PAO [Public Aircraft Operations] are not subject to FAA oversight (p. 1).

The relief from regulatory provisions makes this method of compliance quite convenient for conducting UAS operations, if the entity meets the required eligibility criteria.

The decision matrix for determining Public Aircraft Operations is codified in AC 00-1.1A, p. 12 (FAA, 2014b). A three-pronged test is used to determine if operations qualify as Public Aircraft Operations:

- Aircraft ownership and use

- Crew compliment

- Intended mission

Aircraft Ownership. Federal Public Aircraft Operations must employ aircraft exclusively owned and used by the U.S. government. Similarly, State Public Aircraft Operations must employ aircraft owned [or exclusively leased for 90 consecutive days] and operated by a state entity [including the District of Columbia, U.S. territories, and possessions] (49 CFR 40102a41).

Crew Compliment. Public aircraft flights must not be conducted for commercial purposes and must be manned by either crewmembers or qualified non-crewmembers (49 CFR 40102a41). It is important to note that the term commercial purpose is interpreted broadly by the FAA, and forbids reimbursement to government entities for Public Aircraft Operations (FAA, 2014b).

Intended Mission. Only selected government functions are eligible for designation as a public aircraft. Government functions may include [but are not limited to] national defense, intelligence, firefighting, search and rescue, law enforcement, aeronautical research, or geological resource management (14 CFR 1.1-Public Aircraft (1)(ii)).

Certificates of Authorization. "The COA allows an operator to use a defined block of airspace and includes special safety provisions unique to the proposed operation. COAs usually are issues for a specific period - up to two years in many cases" (FAA, 2016h). Certificates of Authorization are limited to specified state or federal public, governmental flight operations, defined as Public Aircraft according to 14 CFR 1.1.

FAA Legal Interpretations of Public Operations. A June 13, 2014 FAA legal interpretation provided to AFS-80 UAS Integration Office Manager James Williams, overviews how the agency interprets various research endeavors under Certificate of Authorization constraints (Bury \& Petronis, 2014c). The 
agency concedes that public institutions of higher education do indeed qualify as subordinate elements of state government, thereby allowing aircraft meeting the requirements of 49 USC 40102 to be considered public aircraft (Bury \& Petronis, 2014c). Additionally, the agency acknowledges that as long as the proposed activities does not exceed the defined scope of aeronautical research [emphasis added], which are generally defined as the development of aircraft, capabilities, aircraft systems, or aircraft uses, the operation meets the government function requirement (Bury \& Petronis, 2014c). The agency further emphasizes that the results of the proposed research must remain the property of the state, and the flights may not carry equipment or property of another entity (Bury \& Petronis, 2014c). Given compliance with the aforementioned provisions and restrictions, the flight may be considered a public aircraft operation (Bury \& Petronis, 2014c; Bury, 2014). Perhaps most importantly, as long as the aforementioned provisions are met, the flights may be grant funded (Bury \& Petronis, 2014c; Bury, 2014).

In a July 3, 2014 FAA legal interpretation to the UAS Integration Office the FAA also clarified that education was not a valid governmental function under 49 USC 40125(a)(2) for the purposes of operating public aircraft (Bury \& Petronis, 2014b). A separate July 3, 2014 legal interpretation clarified that while the list of government functions contained in 49 USC 40125(a)(2) was not exhaustive, the agency would evaluate additional proposed government functions on the basis of similarity to those defined in the statute (Bury \& Petronis, 2014a).

According to the FAA records, 32 institutions of higher education have been granted Certificates of Authorization (FAA, 2015d).

\section{Civil Operations (Non-Governmental)}

FMRA Section 333. FMRA Section 333 was written to provide civil UAS operators a method to receive FAA approval to conduct low-risk operations in the National Airspace System without adhering to all regulatory provisions normally required by manned aircraft under $14 \mathrm{CFR}$. This provision was designed as a stop-gap measure until the FAA released final UAS rules (FAA, 2016k). Since the FAA's June release of the 14 CFR 107 Small UAS rules, FMRA Section 333 Exemptions now only apply to UAS platforms weighing more than 55 pounds [emphasis added] (FAA, 2016b).

UAS operations that do not meet the criteria for public aircraft operations may request to be granted a special exemption to the requirements specified by Section 332 and 334 of the FAA Modernization and Reform Act (FMRA) of 2012 (U.S. House, 2012). This process authorizes the Secretary of Transportation to individually determine if a UAS can safely operate in the National Airspace System (U.S. House, 2012). The FMRA mandates the Secretary of Transportation to assess UAS characteristics and operational factors such as:

- Size, weight, speed, and operational capability

- Proximity to airports and populated areas

- Operation within visual line of sight

Such factors will be weighed against the likelihood of an unmanned aerial system's likelihood to "create a hazard to users of the National Airspace System or the public or pose a threat to National Security" (FMRA Sec 333(b)(1)). FMRA also requires the Secretary of Transportation to determine if a Certificate of Waiver, Authorization, or Airworthiness is required, based on guidance contained in 49 USC 44704. If a UAS is determined to be able to operate safely in the NAS, the Secretary of Transportation will codify requirements for safe operation.

Option 1: FMRA Section 333 Petition for Exemption of Airworthiness (or other 14 CFR requirements). Dorr and Duquette (2015) cite that generally, section 333 applicants request "relief from 
airworthiness certification...general flight rules, pilot certification requirements, manuals, and maintenance and equipment mandates" (FAA, 2015c, p. 3). The FAA has a specific process for requesting selective 14 CFR regulatory exemptions, codified in 14 CFR 11.61-11.103. To request exemption from selective 14 CFR provisions, an operator must demonstrate (FAA, n.d.a):

- That the selected regulatory requirement(s) create an undue burden

- The proposed operation can maintain an equivalent level of safety to the proposed rule exemption

- The request is in the public interest

"UAS operators who have obtained an exemption must also obtain a COA before conducting UAS operations" (FAA, 2015b, p. C-3).

Option 2: FMRA Section 333 Airworthiness Certification. Airworthiness Certification for UAS platforms may be required, if determined appropriate by the Secretary of Transportation while conducting an assessment of the UAS operation proposed by the respective 333 exemption request.

If required, UAS platforms must meet the same provisions as manned aircraft, as codified by 49 USC 44704 and 44711 (FAA, 2014c). UAS operators may apply for one of three types of airworthiness certifications:

Type Certificate Certification for Special Class Aircraft. This risk-based certification method is used for aircraft for which airworthiness standards have not been published. The FAA instead applies existing airworthiness requirements [such as those contained in 14 CFR Parts 23, 25, 27, 29, 31, 33, and 35], on an individual basis, as applicable to the type design and aircraft, so as to ensure an equivalent level of safety (14 CFR 21.17b). These aircraft are issued a standard airworthiness certificate in accordance with 14 CFR 21.183.

Type Certificate Certification for Restricted Category Aircraft. This airworthiness certification method applies specifically to surplus armed forces, de-militarized UAS aircraft repurposed for civil use, as described in 14 CFR 21.27. Such UAS platforms must have been accepted, serviced, and returned as military surplus in serviceable condition. The process and provisions for issuance of this certificate are contained in FAA order 8110.56A (2008), Restricted Category Type Certification. These aircraft are issued a restricted category special airworthiness certificate in accordance with 14 CFR 21.185b.

Special Airworthiness Certification in the Experimental Category. This certification method applies only to UAS craft purposed for conducting research and development, crew training, or market surveys, or other purposes as prescribed by 14 CFR 21.191. The process and provisions for issuance of this certificate are codified in FAA Order 8130.34C (2013), Airworthiness Certification of Unmanned Aircraft Systems and Optionally Piloted Aircraft. These aircraft are issued an experimental special airworthiness certificate in accordance with 14 CFR 21.191. Carrying property for compensation or hire with an Experimental Category Airworthiness Certificate is prohibited (FAA, 2015a).

"UAS operators who have obtained an airworthiness certificate for their UAS must also obtain a COA before conducting UAS operations" (FAA, 2015b, p. C-3). A COA is also required for UAS operators that have received a FMRA Section 333 Exemption for Airworthiness.

\section{Certificate of Authorization requirements.}

Blanket Certificate of Authorization provisions. Under the previous approval process, the FAA issued a joint Certificate of Authorization to small UAS operators conducting flights under FMRA Section 333 that authorizes national UAS operation in accordance with the Blanket COA provisions, as established in FAA Form 7711-1, UAS COA: Blanket COA for Any Operator with a valid Section 
333 Grant of Exemption (FAA, 2016g; FAA, 2016c). Blanket Certificates of Authorization for small UAS

platforms have been largely replaced by new 14 CFR 107 rules, making this process now defunct.

Certificates of Authorization for UAS platforms weighing more than 55 pounds. UAS platforms weighing more than $55 \mathrm{lbs}$ are still required to apply for COA authorization under the existing FMRA Section 333 exemption process and are subject to operating rules and requirements "the same or similar to operators flying under the small UAS rule" (FAA, 2016b, p. 1).

Previously issued certificates of authorization. Small UAS flights conducted under a previously-issued COA may still be conducted, provided the COA has not expired (FAA, 2016n). Small UAS operators with a valid Section 333 Exemption were given the following key permissions and restrictions under the Blanket COA (FAA, 2016c):

\section{Permissions}

- Applicable only to small Unmanned Aircraft Systems (sUAS) [less than 55 lbs]

- Conduct operations in daytime, VFR conditions

- Altitude must remain at or below 400 feet AGL

- Operations conducted in excess of prescribed distances of the airport reference point of public-use airports, gliderports, or seaports, as published in the Airport Facility Directory and applicable supplements

$\circ 5 \mathrm{NM}$ from airports with an operational control tower

- 3 NM from an airport with a published instrument flight procedure (but without a control tower)

- 2 NM from an airport not having a published instrument flight procedure or operational control tower

○ 2 NM from a heliport

\section{$\underline{\text { Restrictions }}$}

- Requirement for UAS registration

- Requirement for use of visual observers who can monitor the unmanned aircraft and airspace and maintain instantaneous communication with UAS pilot in command

- Restriction from operating Prohibited Areas, Special Flight Rule Areas, the Washington National Capital Region Flight Restricted Zone (FAA, 2016d)

- Remain in compliance with Temporary Flight Restrictions and operational restrictions imposed by Notices to Airmen (NOTAMS)

- Compliance with monthly operations reporting requirements

- Submit reports for UAS incident, accidents, or mishaps that meet specified damage, malfunction, injury, or deviation criteria

- Issuance of a distant NOTAM when conducting UAS operations

- Compliance with operator and equipment requirements, based on airspace class used for UAS operations

- Coordinate and de-conflict operations from Military Training Routes

- Provide advanced notification to affected Air Traffic Control facility (accomplished via NOTAM issuance)

- Conduct communications around airports without an operating control tower in accordance with traffic advisory practices, as prescribed in the FAA Aeronautical Information Manual, 4-1-9

Full Certificate of Authorization application. Operators may submit a subsequent application for a "full" COA, if they want to fly outside the parameters specific by the Blanket COA (FAA, 2016g). 
A full COA application is also required if the UAS platform exceeds 55 pounds (FAA, 2016b). COA applications are filed electronically using the FAA's UAS Civil COA Portal (FAA, 2016g). This process "makes applicable Air Traffic Control facilities aware of proposed UAS operations, and provides the FAA the ability to consider airspace issues unique to airspace operations" (FAA, n.d.c, p. 1). The FAA generally processes civil COA applications within 60 business days, but the approval timeline may be affected by the provisions of the request. Applicants are required to agree to several Civil COA UAS Freedom of Information Act (FOIA) declaration and COA declaration statements to process COA requests (FAA, 2015g). Certificates of Authorization are generally valid for up to two years, but may be renewed or extended (FAA, 2015h). Currently, a full COA is required prior to operating any $U A S$ platform under FMRA Section 333 rules that weighs more than 55 pounds.

Applicability of other 14 CFR requirements. UAS platforms operating under FMRA 333 exemptions are not exempt from other Title 14 CFR regulatory requirements. Operators must remain in compliance with all applicable 14 CFR requirements, including the following notable provisions (FAA, 2014c):

- UAS Registration: As required by 14 CFR 47

- Identification Markings: In accordance with 14 CFR 45(C)

- Noise Certification: As required by 14 CFR 36 [only if airworthiness certification is required]

- Operator Airmen Certification: As prescribed by 14 CFR 61

- Operator Medical Certificate: As prescribed by 14 CFR 67

- Operator TSA Security Eligibility: as required by 14 CFR 61.18

\section{Model Aircraft Operations}

Section 336 Special Rule for Model Aircraft of FAA Modernization and Reform Act of 2012. The final method of compliance is to operate UAS platforms in compliance with the FAA's Special Rule for Model Aircraft Operations, as codified by Section 336 of the FAA Modernization and Reform Act of 2012. In some circumstances, some educational activities can fall under this rule. FMRA provides specific regulatory exemptions for model aircraft operations. Unlike Public Operations and Civil Operations, individuals who operate UAS platforms strictly for hobby and recreational purposes under model aircraft rules and adhere to the FAA's established guidelines do not require agency authorization to fly their platform in the National Airspace System. To qualify as a model aircraft under FMRA, the following criteria must be met (FAA, 2014a):

\section{Definition of Model Aircraft}

- Unmanned aircraft is capable of sustained flight through the atmosphere

- Flown within [natural, un-augmented] visual line of sight of the person operating the aircraft

- Flown for hobby and recreational purposes [which specifically exclude commercial operations for compensation or hire, as defined by 14 CFR 1.1]

\section{Operational Limitations of Model Aircraft}

- Flown strictly for hobby or recreational use

- Operated in accordance with safety guidelines and within the programming of a nationwide community-based organization [such as the Academy of Model Aeronautics]

- Aircraft is limited to not more than $55 \mathrm{lbs}$, unless certified through a design, construction, inspection, flight test, and operational safety program administered by a community-based organization

- Operated in a manner that does not interfere with and gives way to any manned aircraft 
- When flown within 5 miles [SM] of an airport, the model operator provides the airport operator and air traffic control tower (if applicable) with prior notice of the operation (or adhere to a mutually agreed-upon operating procedure for permanent model aircraft locations)

FAA Legal Interpretations of the Special Rule for Model Aircraft. In a legal interpretation issued by the agency, the FAA clarified that AC 91-57 and the provisions applicable to model aircraft "apply only to modelers, and thus specifically excludes its use by persons or companies for business purposes (72 FR 6690, 2007). The FAA further cites that flights conducted "in furtherance of a business, or incidental to the business [emphasis added] would not be a hobby or recreational flight" (FAA, 2014a, p. 10).

In a subsequent policy statement issued on June 18, 2014, the FAA reiterated model aircraft operating guidelines, as presented in Advisory Circular 91-57 (FAA, 1981). Originally issued in 1981, the document specifies model aircraft operators should adhere to the following general guidelines (FAA, 1981; FAA, 2015e):

- Operated at a site away from populated areas and noise-sensitive locations [presumably no longer applicable following release of updated AC 91-57A, September 2, 2015]

- Not operate model aircraft for spectators until the aircraft is tested and deemed airworthy [presumably no longer applicable following release of updated AC 91-57A, September 2, 2015]

- Operated at an altitude not to exceed 400 feet AGL unless operating under a communitybased organization's safety guidelines (AMA, 2016b).

- Operations should be coordinated with the airport operator, control tower or Flight Service Station (FSS), when operated within 3 miles of an airport [proximity modified to operations within 5 miles of an airport; removed notification requirement to FSS in release of updated AC 91-57A, September 2, 2015].

- Always give right of way to manned aircraft

- Recommends the use of observers

Applicability of other 14 CFR requirements. Similar to civil UAS operations authorized under a FMRA Section 333 exemption, model aircraft operations are also subject to certain sections of FAA 14 CFR provisions. The FAA breaks these provisions down into three basic categories of limitations:

- Aircraft operations

○ Not operated in a reckless fashion, adhering to 14 CFR 91.13-91.19.

- Airspace restriction adherence

- Adherence to restrictions of applicable airspace class, Special Use Airspace, Restricted Areas, Prohibited Areas \& Special Flight Rules Area (14 CFR 91.126-91.135; FAA, 2016d).

- Special restrictions

- Adherence to Temporary Flight Restrictions and NOTAMS, as applicable (14 CFR 91.137-91.145; 14 CFR 99.7). 
Succinctly, the FAA expects that model aircraft operators will conduct operations that are comparable in risk to manned operations and do not pose an undue hazard to manned aircraft or people or property on the ground. In its interpretation, the FAA indicates that additional situationally-dependent regulatory provisions may apply to model aircraft, depending on the operation.

FAA Legal Interpretations for Educational Use of UAS for Hobby \& Recreational Purposes. On May 4, 2016, the FAA issued a legal interpretation regarding the use of UAS platforms for educational use, clarifying the following provisions (Govan \& Griffith, 2016):

- Students may conduct model aircraft UAS operations in accordance with FMRA Section 336 in pursuit of aviation education at an accredited educational institution.

- UAS platforms may be operated under FMRA Section 336 model aircraft rules at educational institutions and community-sponsored events, provided the operator is not compensated directly or incidentally related to the operation of the aircraft. The FAA interprets compensation broadly to include both tangible and potentially intangible rewards. The FAA does not consider student receipt of financial aid, work-study, or research assistantship payments as compensation for purposes of complying with FMRA Section 336 criteria (p. 4 Note 9).

- Faculty teaching aviation courses, including those directly applicable to UAS operation, at accredited educational institutions may aid students operating model aircraft conducted under FMRA Section 336 rules. The instructor's operation of the model aircraft must be incidental and secondary to the student's operational control of the platform. The FAA states that "de minimus limited instructor participation in student operation of UAS as a part of coursework does not rise to the level of faculty conducting operation outside of the hobby or recreation construct" (p. 5). According to the West Encyclopedia of Law, 2 $2^{\text {nd }}$ Ed, "De Minimis" is a Latin abbreviation meaning "the law cares not for small things" (2008, p. 1). Conversely, the FAA stops short of issuing carpe blanche approval for faculty UAS instruction, citing that the interpretation only applies in situations where UAS operation is secondary to other course objectives. The agency specifically excludes faculty members from applying the FMRA Section 336 model aircraft rules to courses whose primary function is UAS flight instruction.

- Faculty conducting or supervising UAS research flight operations are not considered hobby and recreational use, as defined by FMRA Section 336.

\section{CFR 107 Small UAS Rule}

Summary of Key Small UAS Regulatory Provisions. The provisions of this regulation codifies existing regulation applicability to 14 CFR (FAA, n.d.b; FAA, 2016f):

- Part 21: Certification for Products \& Articles

- Part 43: Maintenance, Preventative Maintenance, Rebuilding \& Alteration

- Part 61: Certification: Pilots, Flight Instructors, \& Ground Instructors

- Part 91: General Operating \& Flight Rules

- Part 101: Moored Balloons, Kites, Amateur Rockets \& Unmanned Free Balloons

- Part 107: Small UAS Rule

- Part 119: Certification of Air Carriers \& Commercial Operators

- Part 133: Rotorcraft External-Load Operations

- Part 183: Representatives of the Administrator 
Implementation of 14 CFR Part 107 provisions takes place in August 2016 (FAA, 2016m). Once implemented, the 14 CFR Part 107 regulations would preempt the need for civil sUAS operators to apply for an FMRA Section 333 exemption and subsequent COA(s), so long as the planned operation conforms to regulatory specifications contained in Part 107. In addition to the regulatory provisions, UAS operators conducting flights under 14 CFR 107 rules can obtain additional information and guidance from FAA Advisory Circular: AC 107-2, Small Unmanned Aircraft Systems (FAA, 2016i).

Table 1.

Overview of Small Unmanned Aircraft rule codified in 14 CFR Part 107 (FAA, 2016j). Public domain document.

Summary of Small Unmanned Aircraft Rule (Part 107)

The following provisions are included in 14 CFR Part 107, Released June 21, 2016:

Operational Limitations
- Unmanned aircraft must weigh less than 55 lbs. $(25 \mathrm{~kg})$.

- Visual line-of-sight (VLOS) only; the unmanned aircraft must remain within VLOS of the remote pilot in command and the person manipulating the flight controls of the small UAS. Alternatively, the unmanned aircraft must remain within VLOS of the visual observer.

- At all times the small unmanned aircraft must remain close enough to the remote pilot in command and the person manipulating the flight controls of the small UAS for those people to be capable of seeing the aircraft with vision unaided by any device other than corrective lenses.

- Small unmanned aircraft may not operate over any persons not directly participating in the operation, not under a covered structure, and not inside a covered stationary vehicle.

- Daylight-only operations, or civil twilight (30 minutes before official sunrise to 30 minutes after official sunset, local time) with appropriate anti-collision lighting.

- Must yield right of way to other aircraft.

- May use visual observer (VO) but not required.

- First-person view camera cannot satisfy "see-and-avoid" requirement but can be used as long as requirement is satisfied in other ways.

- Maximum groundspeed of $100 \mathrm{mph}$ (87 knots).

- Maximum altitude of 400 feet above ground level (AGL) or, if higher than 400 feet AGL, remain within 400 feet of a structure.

- Minimum weather visibility of 3 miles from control station.

- Operations in Class B, C, D and E airspace are allowed with the required ATC permission.

- Operations in Class G airspace are allowed without ATC permission.

- No person may act as a remote pilot in command or VO for more than one unmanned aircraft operation at one time.

- No operations from a moving aircraft.

- No operations from a moving vehicle unless the operation is over a sparsely populated area.

- No careless or reckless operations.

- No carriage of hazardous materials. 
Table 1. continued

Overview of Small Unmanned Aircraft rule codified in 14 CFR Part 107 (FAA, 2016j). Public domain document.

\begin{tabular}{|c|c|}
\hline $\begin{array}{l}\text { Operational } \\
\text { Limitations }\end{array}$ & $\begin{array}{l}\text { - Requires preflight inspection by the remote pilot in command. } \\
\text { - A person may not operate a small unmanned aircraft if he or she knows or has reason to } \\
\text { know of any physical or mental condition that would interfere with the safe operation of a } \\
\text { small UAS. } \\
\text { - Foreign-registered small unmanned aircraft are allowed to operate under part } 107 \text { if they } \\
\text { satisfy the requirements of part } 375 \text {. } \\
\text { External load operations are allowed if the object being carried by the unmanned aircraft } \\
\text { is securely attached and does not adversely affect the flight characteristics or } \\
\text { controllability of the aircraft. }\end{array}$ \\
\hline & $\begin{array}{l}\text { - Transportation of property for compensation or hire allowed provided that- o The } \\
\text { aircraft, including its attached systems, payload and cargo weigh less than } 55 \text { pounds total; } \\
\text { - The flight is conducted within visual line of sight and not from a moving vehicle or } \\
\text { aircraft; and } \\
\text { - The flight occurs wholly within the bounds of a State and does not involve transport } \\
\text { between (1) Hawaii and another place in Hawaii through airspace outside Hawaii; (2) the } \\
\text { District of Columbia and another place in the District of Columbia; or (3) a territory or } \\
\text { possession of the United States and another place in the same territory or possession. } \\
\text { - Most of the restrictions discussed above are waivable if the applicant demonstrates that his } \\
\text { or her operation can safely be conducted under the terms of a certificate of waiver. }\end{array}$ \\
\hline $\begin{array}{l}\text { Remote Pilot in } \\
\text { Command } \\
\text { Certification } \\
\text { and } \\
\text { Responsibilities }\end{array}$ & 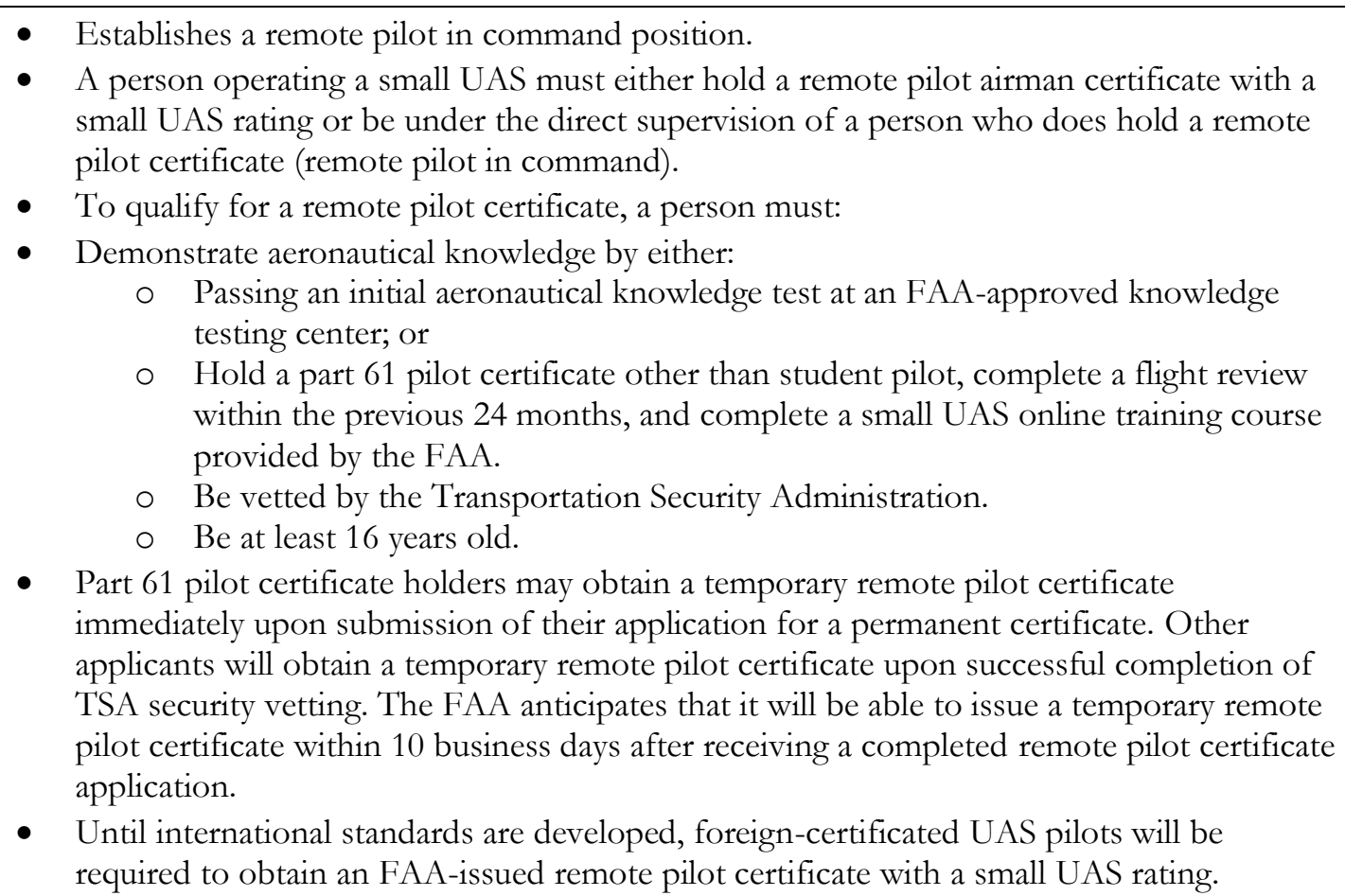 \\
\hline
\end{tabular}


Table 1. continued

Overview of Small Unmanned Aircraft rule codified in 14 CFR Part 107 (FAA, 2016j). Public domain document.

\begin{tabular}{|c|c|}
\hline & $\begin{array}{l}\text { A remote pilot in command must: } \\
\text { - Make available to the FAA, upon request, the small UAS for inspection or testing, and any } \\
\text { associated documents/records required to be kept under the rule. } \\
\text { - Report to the FAA within } 10 \text { days of any operation that results in at least serious injury, } \\
\text { loss of consciousness, or property damage of at least } \$ 500 \text {. } \\
\text { - Conduct a preflight inspection, to include specific aircraft and control station systems } \\
\text { checks, to ensure the small UAS is in a condition for safe operation. } \\
\text { - Ensure that the small unmanned aircraft complies with the existing registration } \\
\text { requirements specified in } ₫ 91.203(a)(2) \text {. } \\
\text { A remote pilot in command may deviate from the requirements of this rule in response to an } \\
\text { in-flight emergency. }\end{array}$ \\
\hline $\begin{array}{l}\text { Aircraft } \\
\text { Requirements }\end{array}$ & $\begin{array}{l}\text { - FAA airworthiness certification is not required. However, the remote pilot in command } \\
\text { must conduct a preflight check of the small UAS to ensure that it is in a condition for safe } \\
\text { operation. }\end{array}$ \\
\hline Model Aircraft & $\begin{array}{l}\text { - Part } 107 \text { does not apply to model aircraft that satisfy all of the criteria specified in section } \\
336 \text { of Public Law } 112-95 \text {. } \\
\text { - The rule codifies the FAA's enforcement authority in part } 101 \text { by prohibiting model } \\
\text { aircraft operators from endangering the safety of the NAS. }\end{array}$ \\
\hline
\end{tabular}

The content of 14 CFR Part 107 is significant, as this rulemaking substantially changes compliance requirements for small UAS operations. A summary of sUAS provisions are presented in Figure 1. Key notable provisions in the proposed sUAS rule include:

- Indefinite UAS operator certificate, issued to individuals who pass an aeronautical knowledge exam with recurrent testing at 24-month intervals

- No requirement for airworthiness certification

- Liberal operating limitations

Operator Certificate. The UAS remote operator certificate allows operators to perform both private and commercial, for-profit functions. The rule does include some notable exceptions such as "air carrier operations, external load and towing operations, international operations, foreign-owned aircraft, public aircraft, model aircraft," and other flying objects covered by 14 CFR Part 101 (FAA, 2016f, p. 43).

The new remote operator certificate can be obtained by individuals at least 16 years old, fluent in English, and physically and mentally able to operate a UAS platform (FAA, 2016a). The primary certification method for issuance of the remote operator certificate is to pass an aeronautical knowledge exam administered by an FAA-approved Knowledge Testing Center (FAA, 2016a). The knowledge exam covers the following key topics (FAA, 2016a, p. 1): 
- *Applicable regulations relating to small unmanned aircraft system rating privileges, limitations, and flight operation

- Airspace classification and operating requirements, and flight restrictions affecting small unmanned aircraft operation

- Aviation weather sources and *effects of weather on small unmanned aircraft performance

- *Small unmanned aircraft loading and performance

- *Emergency procedures

- $*$ Crew resource management

- Radio communication procedures

- *Determining the performance of small unmanned aircraft

- Physiological effects of drugs and alcohol

- Aeronautical decision-making and judgment

- Airport operations

- *Maintenance and preflight inspection procedures

Upon completing the exam, the applicant will apply for the remote operator certificate using the FAA's Integrated Airmen Certificate and/or Rating Application System (IACRA)(FAA, 2016a). The Transportation Security Administration will complete a background check on all remote pilot candidates, and with a successful screening, a permanent certificate will be mailed to the applicant (FAA, 2016a).

A truncated process is available to pilot certificate holders who have completed a flight review in the previous 24 months. In lieu of taking an aeronautical knowledge test, certificated pilots will complete an online computer-based training course administered from the FAA Safety Team (FAAST) website, Part 107 small Unmanned Aircraft Systems (ALC-451) (FAA, 2016a). This course covers selected material from the remote pilot aeronautical knowledge exam, as indicated by asterisk-marked topics. An FAA representative or Designated Pilot Examiner, Airmen Certification Representative, or Certified Flight Instructor will validate the applicant's identity, course completion certificate, and flight review currency (FAA, 2016a). A temporary certificate can be issued on the spot, unless the representative is a CFI, otherwise, a permanent certificate will be mailed to the applicant (FAA, 2016a).

Under current FAA guidelines, operators conducting civil UAS flights under a FMRA Part 333 Exemption sUAS are required to possess at an FAA-issued pilot certificate (FAA, 2014c; FAA, 2016e). Public UAS operations do not require the operator to possess an FAA-issued pilot certificate (FAA, 2016e).

Medical Certificate. In lieu of requiring an FAA medical certificate, the FAA is proposing sUAS operators "self-certify, at the time of their airmen application, that they do not have a medical condition that could interfere with the safe operation of a small UAS (FAA, 2015f, p. 115; FAA, 2016f, p. 396).

Conversely, FMRA Section 333 rules require civil operators to possess an FAA-issued Medical Certificate or "valid state driver's license, depending on the type of certificate held" (FAA, 2014c; FAA, 2016e, p. 16-4-1-3(B)(4)). Public UAS operations are exempt from this requirement (FAA, 2016e).

Airworthiness. Current rules require civil UAS operators to either obtain airworthiness certification or alternatively submit an FMRA Section 333 Exemption to the FAA's aircraft airworthiness requirements. Under the FAA's proposed rule, sUAS operators that adhere to Part 107 requirements would be exempt from obtaining airworthiness certification. Instead, operators would be required to ensure that the UAS platform is safe for flight by conducting an appropriate pre-flight inspection (FAA, 2015f; FAA, 2016f). This determination significantly relieves operators of regulatory burden, as the FAA estimates the current 
certification process for obtaining a type certificate and standard airworthiness certification requires between 3-5 years (FAA, 2015f).

Operational Restrictions. The FAA's 14 CFR Part 107 operational restrictions to sUAS are largely comparable to FMRA Section 333 Blanket COA, with some notable exceptions:

- Elimination of Visual Observer requirement

- Allowance for operations within controlled airspace in close proximity to airports of all classes

- Imposed maximum airspeed limitations of $100 \mathrm{mph}$

- New weather visibility requirements of $3 \mathrm{SM}$

Requesting permission to operate in controlled airspace. Prior to operating in controlled class $\mathrm{B}, \mathrm{C}, \mathrm{D}$, or E airspace, UAS operators must submit an online request via the FAA's UAS website online portal; operators may not contact air traffic control facilities directly (FAA, 2016n).

Requesting a Waiver to Select 14 CFR 107 Operational Requirements. Operators are able to request a certificate of waiver for certain provisions of 14 CFR Part 107 requirements, as indicated by 14 CFR 107.205 (FAA, 2016i):

- 107.25: Operation from a moving vehicle or aircraft (excluding operations that involve the carriage of property of another by aircraft for compensation or hire)

- 107.29: Daylight operation

- 107.31: Visual line of sight operation (excluding operations that involve the carriage of property of another by aircraft for compensation or hire)

- 107.33: Visual observer

- 107.35: Operation of multiple small unmanned aircraft systems

- 107.37(a): Yielding right of way

- 107.39: Operation over people

- 107.41: Operation in certain airspace

- 107.51: Operating limitations for small unmanned aircraft

Certificates of Waiver must be submitted in accordance with instructions contained on the FAA UAS website, www.faa.gov/uas (FAA, 2016i). If an operator wants to conduct operations in a manner not specifically waivable under 14 CFR 107.205, they will need to proceed through the FMRA Section 333 Exemption process to receive flight approval.

\section{Discussion}

For some educational institutions, compliance with the existing regulatory framework for UAS operations may seem complicated. Key issues associated with each UAS regulatory method of compliance are summarized below.

\section{Authorization.}

Considerations: FMRA Section 334 Public Operation with a Public Aircraft and Certificate of

For public institutions, use of FMRA Section 334 provisions may seem to be an attractive option, since they come with few operational restrictions and relatively limited FAA oversight. As long as the institution and flight purpose meet defined eligibility criteria, this method of compliance is ideal for operational approval of large UAS operations and other operational criteria forbidden by Section 333 or 336 
guidance. Since this method of compliance requires issuance of a COA, institutions may need to be proactive in requesting modifications to airspace and operational restrictions, based on evolving needs of their respective public function. Moreover, it is also important to note that COAs are generally approved for a limited two-year period. Institutions must carefully manage COA expiration deadlines and renewal procedures to ensure continued applicability. Continued operations in an expired COA could lead to FAA violations, certificate actions, imposed fines, or other adverse sanctions.

Private educational institutions would generally be ineligible for exercising this method of compliance, since they do not have official status as a recognized state or federal agency. Additionally, designation as a public aircraft operation specifically forbids commercial or for-profit operations, which would also largely disqualify private institutions.

Such authorization would be ideal for public institutions wanting to conduct research in one of the defined government function areas. While the list of recognized government functions is limited in scope, the FAA acknowledges the list is not exhaustive. Such a case could be made for inclusion of other critical government functions, especially if they are closely aligned with designated functions.

It is important to segregate such research from other civil or commercial research projects, as this method of compliance specifically prohibits commercial activities, including carriage of equipment or personnel not directly tied to the approved government function being carried out.

As identified previously, this method of compliance does not limit federal or state government agencies from contracting services for approved governmental functions. In this limited case, the educational institution would not be the actual holder of the Certificate of Authorization (Bury \& Petronis, 2014c).

\section{Considerations: FMRA Section 333 Civil Operations}

Section 333 Exemptions are usually no longer appropriate for most institutions of higher learning, unless they intend to operate a UAS platform that exceeds the eligibility restrictions to comply with 14 CFR Part 107 rules.

The key benefits of this method of compliance is that all educational institutions are eligible for inclusion. More importantly, a Section 333 Grant of Exemption further allows the educational entity to conduct UAS operations for most commercial or for-profit purposes, as defined by their exemption request. This method also provides an option for relief from complicated and time-consuming airworthiness certification and certain provisions of 14 CFR. For most low-risk operations, the FAA has determined that airworthiness certification is not generally necessary. Additionally, this method of compliance generally enjoys a relatively rapid FAA approval timeline of 60 days, but may take longer based on the complexity of the operational request. Like COAs issued for public aircraft operations, approval is generally granted for a period of up to two years, but can usually be renewed as necessary.

The most notable disadvantage of this method of compliance is the requirement that UAS platforms operated under Section 333 must be operated by certificated airmen holding a valid medical certificate. Many institutions may find this provision unnecessarily restrictive, provided the highly automated features of many commercially-available UAS platforms. Nevertheless, compliance with the restrictions and provisions articulated by the blanket COA requires an individual to have a relatively thorough understanding of aeronautical knowledge, comparable to that of a certificated pilot. This method of compliance generally requires the use of visual observers. Succinctly, the manpower and qualification requirements needed to employ this method of compliance are usually high.

Succinctly, this method of compliance is really only appropriate for organizations that are planning to fly a UAS exceeding 55 pounds or holders of existing FMRA Section 333 exemptions. It is important to note 
for existing 333 Exemption holders that the FAA does not permit "mixing" issued COA provisions with 14 CFR 107 requirements. For example, an operator with a valid 14 CFR 107 Remote Operator certificate would not be in compliance with FAA requirements if the COA specified that a Private Pilot Certificate was required. To ensure regulatory compliance, operators must ensure that flights are conducted wholly in accordance with their 333 Grant of Exemption/COA or wholly in compliance with 14 CFR Part 107 regulations.

\section{Considerations: FMRA Section 336 Model Aircraft Operations}

The FAA's recent May 4, 2016, legal interpretation of Educational Use of UAS for Hobby and Recreational purposes expanded the use of this method of compliance to specifically include certain educational and demonstration purposes. The provisions contained within the FAA's interpretation significantly reduce the compliance burden for limited-scope instructional use of small UAS platforms. Now, both students and instructors can utilize UAS platforms to augment their classroom training, while remaining in compliance with very generous FMRA Section 336 Model Aircraft rules. Compliance under Model Aircraft rules specifically forbids its application for research purposes, but it can be used for classroom educational purposes.

Under the revised educational use interpretation, instructors can provide de minimis instruction and intervention for students using small UAS platforms in advancement of their educational courses. Simultaneously, the FAA excludes UAS flight instruction and presumably other UAS instruction in which UAS flight would be regularly expected and performed. The FAA finds that "de minimis" limited instructor participation in student operation of UAS as part of coursework does not rise to the level of faculty conducting an operation outside of the hobby or recreation construct. Unfortunately, the FAA leaves the definition of "de minimis" up to the mind of the operator. In that, the FAA has neither defined "de minimis" nor addressed its definition in previous cases brought before an Administrative Law Judge or the National Transportation Safety Board. The only glimpse into the FAA's definition is a largely unprecedential case brought before the Administrator of Airports in which the Acting Associate Administrator for Airports indicated that the use of the term "de minimis" is subjective and is determined largely upon a case by case basis (Alaska Airlines et al. v. Los Angeles World Airports et al., 2007). The lack of specific guidance or an objective de minimis compliance test make this provision highly subjective to enforcement. Presumably, institutions should be conservative in their application of UAS operations under this rule, assuming that the FAA will take a similarly conservative stance when determining de minimis instructor participation.

This compliance method does not require airworthiness certification, specified pilot qualification, a medical certificate; nor does it mandate the use of visual observers. While the qualification and manpower requirements for compliance under this method are generous, institutions should carefully consider the level of aeronautical knowledge, training, and experience of instructional staff before conducting operations to ensure that UAS flights are conducted safely and in compliance with the Special Rule for Model Aircraft provisions.

Use of the Special Rule for Model Aircraft requires that participants conform to operating within the safety guidelines and programming of a nationwide community-based organization, such as the Academy of Model Aeronautics. Institutions should review organizational and individual membership requirements, as well as recommended operational and safety practices prescribed by such organizations to remain in compliance with this provision, if operations are conducted under Special Model Aircraft rules.

Operations conducted under Special Model Aircraft rules eases regulatory restrictions on UAS flights conducted in proximity to airports, requiring only prior coordination with airport operators or applicable air traffic control facilities prior to commencing operations. 
Importantly, the FAA's interpretation implies this method of compliance is also applicable to commercial or for profit, accredited educational institutions. While the FAA does not specifically define accreditation requirements, they presumably correspond to Department of Education standards. This could seemingly apply to all levels and types of recognized primary, secondary, and post-secondary education or technical training institutions. Notably, private or for-profit institutions were previously forbidden from operating under the Special Model Aircraft rules, due to the existing prohibition on commercial operations. The FAA's release of the May 4, 2016, legal interpretation of Educational Use of UAS for Hobby and Recreational Purposes, provides relief for private, or for-profit institutional academic use of UAS platforms under FMRA Section 336 rules. It is important to highlight that the FAA's interpretation did not rescind its prohibition on commercial use or receipt of compensation for UAS flights, merely articulated that certain academic functions are not considered commercial in nature. While not specifically addressed by the FAA, institutions should be wary of adding UAS lab fees to courses that operate under Section 336 rules, as this approach could be seen with an unkind eye by the FAA to be receiving compensation for UAS flight operations.

It is likely that most institutions will benefit from conducting operations under Special Model Aircraft rules by streamlining and increasing student access to UAS learning opportunities. Institutions should be cautious when implementing UAS into their academic programs; however, as the relatively limited regulatory requirements, knowledge, and training required to operate under this method of compliance could result in operators being ill-prepared or trained to conduct flights safely.

Community Based Organization Programming. One required provision for operating under FMRA Section 336 rules is that the individual must operate their aircraft within the safety guidelines and programming of a nationwide community-based organization, such as the Academy of Model Aeronautics (AMA). The AMA offers several categories of membership applicable to educational UAS including:

Individual Membership. There are several benefits to AMA membership; however, access to the program's liability, accident, and medical coverage programs are the most significant.

Model Aviation Student Club (MASC). The AMA describes MASC as a (AMA, n.d.a):

Club chartering program for school aeromodelling clubs. MASC gives schools the opportunity to teach aeromodelling curriculum in their school. Some of the membership benefits for MASC include free AMA membership for the faculty sponsor and students, full AMA insurance benefits, scholarship opportunities, and access to the AMA's educational resources. (p. 2)

Student members less than 19 years old are free. The AMA also waives MASC club chartering fees (AMA, n.d.d). MASC clubs are eligible to purchase optional site owners insurance (AMA, n.d.d).

University Model Aviation Student Club (UMASC). The AMA started a similar initiative to MASC for university students in 2015, dubbed UMASC. The AMA describes UMASC as (AMA, n.d.a):

A club charter program for university students with an interest in model aviation to form a club within their college or university. The faculty sponsor or advisor will receive a free AMA membership and monthly hardcopy of Model Aviation magazine. Students will receive AMA membership at a discounted rate, and a monthly digital copy of Model Aviation magazine. Students will also be eligible for AMA's scholarship opportunities (p. 2)

Student members of UMASC clubs can purchase $\$ 15$ discounted, annual memberships (AMA, n.d.e). The club chartering fee is $\$ 40$, annually (AMA, n.d.e). UMASC clubs are eligible to purchase optional site owners insurance (AMA, n.d.e). 
Flying Site Assistance Program. One valuable service offered by the AMA includes a specialist and resources to help new member clubs obtain a flying site. This includes instructions about site selection, planning, organizing, and coordinating with site owners (AMA, 2016a). The AMA also provides recommendations for safety flying rules and operational rules that address topics such as flying times, required permitting, and emergencies (AMA, 2008).

The AMA also offers additional programs to support flight sites, such as the Flying Site Development \& Improvement Grant Program, which provides 10\% matching funds to site improvements on a competitive application basis (AMA, 2016a). The AMA also furnishes grants to AMA chartered clubs to defray the cost of site cleanup in the event of a natural disaster (AMA, 2016a).

Site Ownership Liability Insurance. The AMA provides the opportunity for site owners, which can include clubs based at educational institutions, to purchase highly affordable liability insurance coverage (AMA, n.d.c):

The AMA General Liability Insurance Program insuring the AMA, members, and clubs for liability resulting from aeromodelling activities includes a broad and unique coverage for site owners. AMA recognizes the importance of providing site owners with insurance to protect them for potential liability for injury or damage resulting from club activities on a flying site and has negotiated a custom policy with a major insurer to provide such coverage. (p. 1)

Site owner's insurance is issued through Westchester Surplus Lines Insurance Company and provides site owners with up to $\$ 2,500,000$ of coverage per occurrence with a maximum claim payout of $\$ 5,000,000$ per site each year (AMA, n.d.c). Site owners are issued certificates of insurance naming them as additional insured parties (AMA, n.d.c). More importantly, site owner's coverage is primary insurance, providing liability protection prior to other site owner policies (AMA, n.d.c). Most importantly, site owner's coverage remains in-force, even if an AMA member or AMA club conducts an activity that voids the club's coverage (AMA, n.d.c). Yearly coverage is issued for $\$ 80$ or alternatively, date-constrained, single-event coverage can be purchased for $\$ 25$ (AMA, n.d.b).

In addition to providing valuable safety and operational resources, membership in the AMA provides members and institutions access to very inexpensive liability insurance coverage. It is for this key reason that the authors recommend that whenever possible and appropriate, institutions conduct UAS operations within the membership guidelines and programming of the AMA and in accordance with FMRA Section 336 rules.

\section{Considerations: Small UAS 14 CFR Part 107}

Operations under 14 CFR 107 provide institutions with maximum flexibility in which to conduct UAS operations. Remote pilot certification and is relatively simple and easy to obtain for most individuals. Flight restrictions are very generous and should accommodate most educational requirements. Operating under 14 CFR 107 rules largely eliminates the potential consequences for inadvertently conducting illegal commercial operations under FMRA Section 336 rules.

Many institutions will likely prefer to operate under 14 CFR 107 rules, as opposed to continued operations under an existing FMRA Section 333 exemption, due in large part to the simplified operator certification, medical, platform and airworthiness provisions. Moreover, the regulation provides a simple mechanism for requesting an operational waiver for selected 14 CFR 107 provisions.

Succinctly, these proposed provisions offer significant relief from many burdensome 14 CFR provisions that apply to manned aircraft and FMRA Section 333/COA holders. Since pilot certification under 14 CFR 107 does not require a UAS flight evaluation, institutions should be aware of the aeronautical 
knowledge, training, and experience of operators to ensure they are adequately prepared to conduct safe flight operations.

\section{Conclusions}

\section{How can educational institutions legally incorporate use of Unmanned Aircraft Systems?}

This research determined that there are currently five methods for educational institutions to appropriately comply with existing FAA UAS regulations:

- Operation as a Public Aircraft with an approved COA

- Operation under FMRA Section 333 with Airworthiness Certification and a COA

- Operation under FMRA Section 333 with Airworthiness Exemption and a COA

- Operation under FMRA Section 336 Special Rule for Model Aircraft

- Operation in accordance with 14 CFR Part 107

It is expected that the 14 CFR 107 process will largely replace the vast majority of operations currently certified under FMRA Section 333. Only UAS platforms that exceed 55 pounds and those that are not waivable under 14 CFR 107.205 are likely to continue certification under the FMRA Section 333 Exemption Process.

What legal or operational conditions or limitations are associated with educational use of Unmanned Aircraft Systems?

The key legal issues that arise from educational use of UAS include:

- Potential for illegal commercial operation under FMRA Section 336 rules

- Potential for personal or institutional liability (or vicarious liability) for injuries or damage resulting from faculty, staff, or student use of UAS

- Potential for FAA non-compliance/violation, possibly resulting in civil enforcement or operator certificate action

\section{What legal issues are left unanswered by the FAA's guidance on educational use of UAS?}

It is clear that existing regulations and legal interpretations leave several unclear lingering legal issues. Foremost is the FAA's "de minimis" requirement for educational use of UAS under FMRA Section 336 rules. The lack of a formal de minimis testing process coupled with the limited interpretation of its applicability to certain courses is likely to lead to wide differences in implementation. Clearly the FAA needs to provide further clarifying guidance in this area.

\section{Recommendations}

\section{Decision Matrix}

To aid educational administrators in selecting the most appropriate method of compliance under existing FAA rules, the authors have included a summary decision matrix in Figure 1 that codify the most important aspects of each method of compliance.

\section{UAS Institutional Review Board \& Steering Committee}

The operation of UAS platforms carries the potential for significant legal liability, if not carefully managed. Individual employees could be subjected to substantial lawsuits for personal injury or damage 
resulting from UAS operations. Institutions can be subject to vicarious liability for UAS operation conducted by their employees. Vicarious liability is defined as "a legal doctrine that assigns liability for an injury [or damage] to a person who did not cause the injury [or damage] but who has a particular relationship to a person who did act negligently"; one such example of this relationship is between an employer and employee ("Vicarious Liability," n.d., p. 1). The legal theory known as "respondeat superior" opens the door for an employing institution to be vicariously liable for the omissions or negligent acts by instructors or professors acting within the scope of their employment. In other words, an institution could potentially be held liable for the damages caused by an instructor/professor when piloting or using an unmanned aerial system in the classroom. The question within this theory of liability is always whether at the time the employee committed the negligent act or omission the employer had the "right of control" over the employee. Essentially, this asks whether the institution had the authority to direct the conduct of the employee in the performance of the negligent act. The question of whether a principal-agency relationship exists is generally one of fact, a question left for a jury. This liability would likely extend to contingent faculty members, as well, since many institutions employ adjunct faculty members as part-time employees rather than individual contract employees. Moreover, operators could also be subjected to civil penalty or other administrative action from violation of FAA regulations.

As a result, the authors propose that institutions planning to conduct UAS operations establish a Review Board and Steering Committee composed of UAS experts, college administrators, instructors and other applicable parties to formulate policy and guidance for instructor, staff, and student use of UAS. The goal of the committee would be to provide guidance to ensure UAS use is conducted safely, legally, and in a manner that best protects the institution and its members from potential liability.

The authors suggest that such a committee's specific duties may include, but are not limited to:

- Provide expert advice to college administrators in establishing UAS campus use policies

- Develop designated campus UAS operations areas and coordinate with external entities to develop MOU/LOAs with airport operators, air traffic control facilities, and other applicable agencies

- Establish training and flight practice opportunities for college faculty and staff wanting to use UAS platforms in their programs or courses

- Ensure college compliance with UAS registration requirements

- Evaluate department or program requests to use UAS to ensure compliance with $14 \mathrm{CFR}$ 107 or PL 112-95 Section 336 rules.

- Compile and maintain a list of college staff members qualified to operate UAS platforms for educational activities that cannot be conducted under PL 112-95 Section 336 hobby and recreational use rules

- Provide safety and training opportunities for institutional UAS users

- Track institutional and individual Academy of Model Aeronautics memberships, in accordance with PL 112-95 Section 336 requirements

- Ensure compliance with 14 CFR 107 accident reporting requirements

- Promote the benefits and potential uses of UAS in education

- Evaluate risk associated with 14 CFR 107 operational waivers; Assist operators with submitting 14 CFR 107 Certificate of Waiver requests

- Assist in managing compliance with institutional, primary, and supplemental liability insurance requirements for UAS operation

Institutions with existing FMRA Section 333 Exemptions/COAs or operating under public aircraft rules/COAs may also task the steering committee as follows: 
- Assess planned UAS operations to ensure compliance with assigned COA provisions, such as operational restrictions, pilot qualifications, notification requirements, etc.

- Ensure currency of assigned FMRA Section 333 Exemption/COA(s) and facilitate biennial renewals, as required

\section{Additional Research}

The authors recommend additional research regarding risk mitigation and liability protection for teachers and institutional operation of UAS platforms. Additional research is also required to codify state or local laws and ordnances that may impact educational use of unmanned aircraft systems. 


\section{Disclaimer}

Unless otherwise specifically cited, information and commentary throughout the document represent the views opinions and interpretations of the authors alone and may or may not represent those held by the Federal Aviation Administration. Readers should not use information contained in this document in lieu of legal advice from a qualified attorney with knowledge of FAA regulations and existing UAS rules.

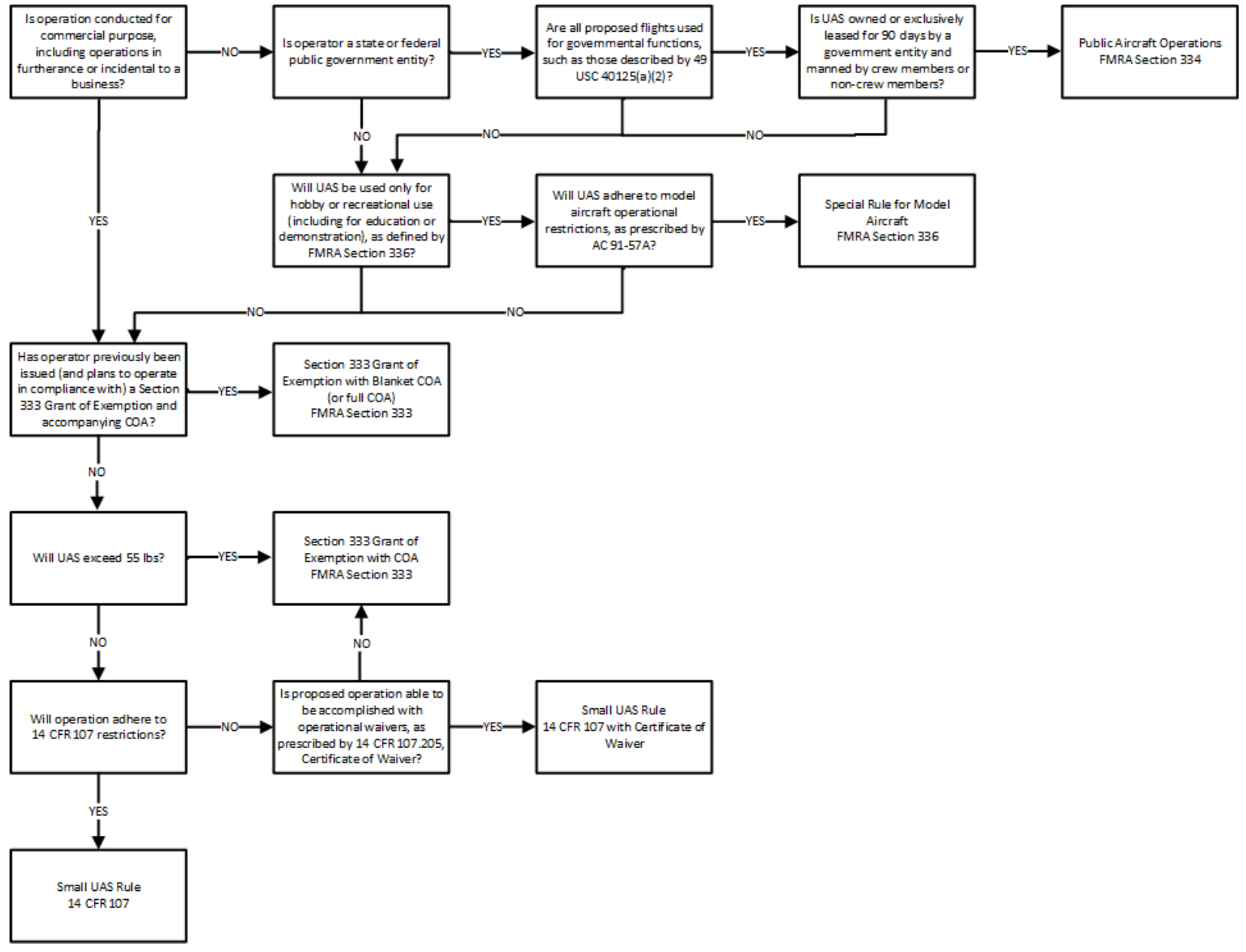

Figure 1. UAS Regulatory Compliance Decision Matrix. 


\section{References}

Academy of Model Aeronautics. (n.d.a) AMA Education Programs Overview

[Brochure]. Muncie, IN: AMA.

Academy of Model Aeronautics. (n.d.b). Flying Site Information. Retrieved from

http://www.modelaircraft.org/files/904.pdf

Academy of Model Aeronautics. (n.d.c). Liability Insurance Program for Site

Owners. Retrieved from http://www.modelaircraft.org/files/

2015SiteOwnerSummary.pdf

Academy of Model Aeronautics. (n.d.d). Model Aviation Student Club Chartering

Guide. Retrieved from http:/ / amaflightschool.org/sites/default/files/

2016\%20MASC\%20Club\%20Charter\%20Guide_0.pdf

Academy of Model Aeronautics. (n.d.e). University Model Aviation Student Club

Chartering Guide. Retrieved from http:/ /www.modelaircraft.org/

files/UMASCapplication.pdf

Academy of Model Aeronautics. (2008). Flying Site Safety and Operational

Rules. Retrieved from http://www.modelaircraft.org/files/535-b.pdf

Academy of Model Aeronautics. (2016a). Academy of Model Aeronautics

Membership Manual 2016. Retrieved from

https://www.modelaircraft.org/files/memanual.pdf

Academy of Model Aeronautics. (2016b). Member communication: clarification

of 400' rule [Memorandum]. Retrieved from http://view.exacttarget.com/

$? \mathrm{j}=$ fe5b127172660c7f7112\&m $=$ fec $815777563057 \mathrm{a} \& \mathrm{l}=\mathrm{fdbd} 157471610 \mathrm{~d} 757214777561 \& \mathrm{l}=\mathrm{fe} 8 \mathrm{~b} 1373$

$7 \mathrm{~d} 6 \mathrm{c} 067 \mathrm{~d} 7 \mathrm{~d} \& \mathrm{~s}=\mathrm{fe} 191 \mathrm{c} 78706306797 \mathrm{c1d} 72 \& j \mathrm{~b}=\mathrm{ffcf} 14 \& \mathrm{k} u=\mathrm{fe} 1 \mathrm{f1} 17573630175771 \mathrm{~d} 71 \& \mathrm{r}=0$

Alaska Airlines et al. v. Los Angeles World Airports et al., 12-13 (DOT/ALJ,

2007). Retrieved from http://www.airlineinfo.com/ostpdf65/939.pdf

Bury, M.W. (2014). Letter to Dr. Benjamin W. Heumann [Memorandum].

Washington DC: Federal Aviation Administration. Retrieved from

https://www.faa.gov/about/office_org/headquarters_offices/agc/pol_adjudication/agc200/Interpr etations/data/interps/2014/Heumann-Central $\% 20$

Michigan \%20University\%20-\%20(2014)\%20Legal\%20Interpretation.pdf

Bury, M.W. \& Petronis, K.L. (2014a). Clarification of June 13, 2014

Interpretation on Research Using UAS [Memorandum]. Washington DC: Federal Aviation

Administration. Retrieved from https://www.faa.gov/about/office_org/headquarters_offices/agc/

pol_adjudication/agc200/interpretations/data/interps/2014/williams-afs-80\%20clarification $\% 20$ -

$\% 20(2014) \% 20$ legal $\% 20$ interpretation.pdf 
Bury, M.W. \& Petronis, K.L. (2014b). Operation of UAS as Public Aircraft for

Educational Purposes [Memorandum]. Washington DC: Federal Aviation Administration. Retrieved from https://www.faa.gov/about/office_org/

headquarters_offices/agc/pol_adjudication/agc200/interpretations/data/interps/2014/williams-afs$80 \% 20$ education $\% 20 \% 20(2014) \% 201$ legal $\%$

20interpretation.pdf

Bury, M.W. \& Petronis, K.L. (2014c). UAS Operations by Public Universities for

Aeronautical Research [Memorandum]. Washington DC: Federal Aviation Administration. Retrieved from http://www.faa.gov/about/ office_org/headquarters_offices/agc/pol_adjudication/agc200/ interpretations/data/interps/2014/williams-afs-80\%20-\%20(2014)\%20legal\%20interpretation.pdf

De Minimis. (n.d.) West's Encyclopedia of American Law, 2nd Ed. (2008).

Retrieved from http://legal-dictionary.thefreedictionary.com/De+Minimis

Federal Aviation Administration. (n.d.a) Guidelines for submitting a petition for exemption. Retrieved from http://aes.faa.gov/Petition/

Federal Aviation Administration. (n.d.b) Overview of Small UAS Notice of Proposed Rulemaking: Summary of Major Provisions of Proposed Part 107. Retrieved from https://www.faa.gov/regulations_policies/rulemaking/ media/021515_sUAS_Summary.pdf

Federal Aviation Administration. (n.d.c) UAS Civil COA. Retrieved from https://oeaaa.faa.gov/oeaaa/external/uas/portal.jsp

Federal Aviation Administration. (1981). Model Aircraft Operating Standards [Advisory Circular, AC 91-57]. Retrieved from http://www.faa.gov/ documentLibrary/media/Advisory_Circular/91-57.pdf

Federal Aviation Administration. (2014a). Interpretation of the Special Rule for Model Aircraft [Docket no. FAA-2014-0396]. Retrieved from https://www.faa.gov/uas/media/model_aircraft_spec_rule.pdf

Federal Aviation Administration. (2014b). Public Aircraft Operations [Advisory Circular, AC 00-1.1A]. Retrieved from https://www.faa.gov/ documentLibrary/media/Advisory_Circular/AC_00-1_1A.pdf

Federal Aviation Administration. (2014c). Public guidance for petitions for exemption filed under section 333. Retrieved from https://www.faa.gov/ uas/legislative_programs/section_333/how_to_file_a_petition/media/section333_public_guidance. pdf

Federal Aviation Administration. (2015a). Civil Operations (Non-Governmental). Retrieved from https://www.faa.gov/uas/civil_operations/

Federal Aviation Administration (2015b). Education, Compliance, and Enforcement of Unauthorized Unmanned Aircraft Systems Operators [Notice, N 8900.313]. Retrieved from https://www.faa.gov/ documentLibrary/media/Notice/N_8900.313.pdf 
Federal Aviation Administration. (2015c). Fact sheet: Unmanned Aircraft Systems. Retrieved from http://www.faa.gov/uas/faq/media/ 1009_UAS_Fact_Sheet.pdf

Federal Aviation Administration. (2015d). Freedom of information act responses. Retrieved from https:/ /www.faa.gov/uas/public_operations/ foia_responses/

Federal Aviation Administration. (2015e). Model Aircraft Operating Standards [Advisory Circular, AC 91-57A]. Retrieved from https://www.faa.gov/ documentLibrary/media/Advisory_Circular/AC_91-57A.pdf

Federal Aviation Administration. (2015f). Operation and Certification of Small Unmanned Aircraft Systems [Docket No. FAA-2015-0150; Notice No. 15-01]. Retrieved from https://www.faa.gov/regulations_policies/rulemaking/ recently_published/media/2120-AJ60_NPRM_2-15-2015_joint_signature.pdf

Federal Aviation Administration. (2015g) UAS Civil FAQs. Retrieved from https://oeaaa.faa.gov/oeaaa/external/uas/content/UASCivilCOAFAQs.jsp

Federal Aviation Administration. (2015h). Unmanned Aircraft Operations in the National Airspace System [Notice Joint Order, N JO 7210.891]. Retrieved from http://www.faa.gov/documentLibrary/media/Notice/ Notice_UAS_7210.891.pdf

Federal Aviation Administration. (2016a). Becoming a Pilot. Retrieved from https://www.faa.gov/uas/getting_started/fly_for_work_business/becoming_a_pilot/

Federal Aviation Administration. (2016b). Beyond the Basics. Retrieved from https://www.faa.gov/uas/getting_started/fly_for_work_business/beyond_the_basics/

Federal Aviation Administration. (2016c). Blanket COA for any Operator issued a valid Section 333 Grant of Exemption [FAA Form 7711-1]. Retrieved from https://www.faa.gov/uas/legislative_programs/section_333/ how_to_file_a_petition/media/Section-333-Blanket-400-COA-Effective.pdf

Federal Aviation Administration. (2016d). DC is a No Drone Zone. Retrieved from http://www.faa.gov/uas/no_drone_zone/dc/

Federal Aviation Administration. (2016e). Flight Standards Information Management System [FSIMS, 8900.1] Retrieved from http:// fsims.faa.gov/PICResults.aspx?mode $=$ EBookContents\&restricttocategory $=$ all $\sim$ menu

Federal Aviation Administration (2016f). Operation and Certification of Small Unmanned Aircraft Systems [Docket No. FAA-2015-0150]. Retrieved from https://www.faa.gov/uas/media/RIN_2120-AJ60_Clean_Signed.pdf

Federal Aviation Administration. (2016g). Petitioning for exemption under section 333. Retrieved from https://www.faa.gov/uas/legislative_ programs/section_333/how_to_file_a_petition/ 
Federal Aviation Administration. (2016h). Public operations (Governmental). Retrieved from https://www.faa.gov/uas/public_operations/

Federal Aviation Administration. (2016i). Small Unmanned Aircraft Systems [Advisory Circular, AC 107-2]. Retrieved from https://www.faa.gov/ uas/media/AC_107-2_AFS-1_Signed.pdf

Federal Aviation Administration. (2016j). Summary of Small Unmanned Aircraft Rule (Part 107). Retrieved from https://www.faa.gov/uas/media/ Part_107_Summary.pdf

Federal Aviation Administration. (2016k). UAS Registration Q\&A. Retrieved from https://www.faa.gov/uas/registration/faqs/

Federal Aviation Administration. (2016l). UAS Symposium Broadens Dialogue on Integration. Retrieved from https://www.faa.gov/mobile/ index.cfm?event $=$ news.read\&update $=85488$

Federal Aviation Administration. (2016m). Unmanned Aircraft Systems. Retrieved from https://www.faa.gov/uas/

Federal Aviation Administration. (2016n). Unmanned Aircraft Systems (UAS) Frequently Asked Questions/Help. Retrieved from https://www.faa.gov/ uas/faqs/

Govan, R.C. \& Griffith, D.E. (2016). Educational Use of Unmanned Aircraft Systems [Memorandum]. Washington DC: Federal Aviation Administration. Retrieved from https://www.faa.gov/uas/ regulations_policies/media/Interpretation-Educational-Use-of-UAS.pdf

Marchman, J.L. (2016). Flying in no-man's land: The use of drones at schools. Texas Association of School Business Officials Report. Retrieved from https://higherlogicdownload.s3.amazonaws.com/TASBO/UploadedImages/6fca71d0-7e6c-40bfa971-8e62e74a7975/Report $\% 20$ on $\% 20$ Drone $\% 20$

Use $\% 20$ at $\% 20$ Schools.pdf

Masunaga, S. (2016). FAA predicts that 4.3 million hobbyist drones will be sold by 2020. LA Times. Retrieved from http://www.latimes.com/business/la-fi-drone-forecast20160325-htmlstory.html

McNabb, M. (2016). When will small UAS rule be published: The embarrassing timeline. DroneLife. Retrieved from http://dronelife.com/2016/05/20/ timeline-of-small-uas-rule/

Unmanned Aircraft Operations in the National Airspace System. 72 FR 6689 (February 13, 2007)(to be codified at 14 CFR Part 91). Retrieved from https://www.gpo.gov/fdsys/granule/FR-2007-02-13/E7-2402 
U.S. House. (2012). FAA Modernization and Reform Act of 2012, Conference Report (to accompany H.R. 658) [Report 112-381]. Retrieved from https://www.gpo.gov/fdsys/pkg/CRPT-112hrpt381/pdf/CRPT-112hrpt381.pdf

Vicarious Liability. (n.d.). West Encyclopedia of American Law, 2nd Ed. (2008).

Retrieved from http://legal-dictionary.thefreedictionary.com/ vicarious +liability 